\title{
Plasma pharmacokinetics and synovial concentrations of S-flurbiprofen plaster in humans
}

\author{
Ikuko Yataba $^{1}$ - Noboru Otsuka ${ }^{1}$ Isao Matsushita ${ }^{1} \cdot$ Miho Kamezawa $^{2}$. \\ Ichimaro Yamada $^{2}$ - Sigeru Sasaki ${ }^{3}$ - Kazuo Uebaba ${ }^{4} \cdot$ Hideo Matsumoto ${ }^{5}$. \\ Yuichi Hoshino 6
}

Received: 9 August 2015 / Accepted: 25 September 2015 / Published online: 6 October 2015

(C) The Author(s) 2015. This article is published with open access at Springerlink.com

\begin{abstract}
Purpose The purpose of this study is to investigate the pharmacokinetics and deep tissue penetration capability of the newly developed S-flurbiprofen plaster (SFPP) in humans. Methods Study 1: SFPP tape-type patch (2-60 mg) was applied to the lower back for $24 \mathrm{~h}$ in healthy adult volunteers. Sflurbiprofen (SFP) plasma concentration was measured over time to examine SFP pharmacokinetics.

Study 2: SFPP (20 mg) was applied for $12 \mathrm{~h}$ to the affected knee of osteoarthritis (OA) patients who were scheduled for total knee arthroplasty. Deep tissues (synovial tissue and synovial fluid) were collected during surgery to compare SFP concentrations after application of SFPP or a commercially available flurbiprofen (FP) gel-type patch.

Results Study 1: The plasma concentration of SFP was sustained during 24-h topical application of the SFPP, showing a high percutaneous absorption ratio of 51.4-72.2\%. $\mathrm{C}_{\max }$ and $\mathrm{AUC}_{0-\infty}$ were dose-proportional.
\end{abstract}

Electronic supplementary material The online version of this article (doi:10.1007/s00228-015-1960-6) contains supplementary material, which is available to authorized users.

Noboru Otsuka

n-otsuka@so.taisho.co.jp

1 Development Headquarters, Taisho Pharmaceutical Co. Ltd, 3-24-1 Takada, Toshima-ku, Tokyo 170-8633, Japan

2 Mitsubishi Tanabe Pharma Corporation, Tokyo, Japan

3 Sapporo Tsukisamu Chuo Orthopedics, Sapporo, Japan

4 Faculty of Health Science, Teikyo Heisei University, Ichihara, Japan

5 Institute for Integrated Sports Medicine, School of Medicine, Keio University, Tokyo, Japan

6 Orthopedics Surgery, School of Medicine, Jichi Medical University, Shimotsuke, Japan
Study 2: After application of the SFPP for $12 \mathrm{~h}$, SFP concentrations in the synovial tissue and synovial fluid were 14.8fold ( $p=0.002)$ and 32.7-fold $(p<0.001)$ higher, respectively, than those achieved by the FP patch.

Conclusions Sustained plasma concentration of SFP and high percutaneous absorption ratio was observed after 24-h topical application of the SFPP. Compared to the FP patch, the SFPP showed superior percutaneous absorption and greater tissue penetration of SFP into the synovial tissue. Greater tissue penetration of the SFPP seemed to be primarily due to its formulation. Thus, SFPP is expected to show higher efficacy for the treatment of knee OA.

Keywords Topical NSAIDs $\cdot$ S-flurbiprofen .

Pharmacokinetics · Tissue concentration · Synovial tissue

\section{Introduction}

Major symptoms of osteoarthritis (OA) are chronic pain and functional disorder derived from synovitis, both of which substantially decrease the quality of life of afflicted patients [1, 2]. Oral and topical nonsteroidal anti-inflammatory drugs (NSAIDs) have been widely used to treat the symptoms of $\mathrm{OA}$ and such use is recommended by various guidelines [3-5].

Because pain severity in OA patients is associated with the degree of synovitis [6, 7], it is important to confirm the drug concentration in synovial tissue when predicting the therapeutic effect of topical NSAIDs [8, 9]. Therefore, drug concentrations in knee joint tissue after application of topical NSAIDs have been determined [8-13].

We developed a new generation topical NSAID patch, the S-flurbiprofen plaster (SFPP). S-flurbiprofen (SFP) is an enantiomer of racemic flurbiprofen (FP), and SFP potently 
inhibits cyclooxygenase (COX)- 1 and COX-2, whereas the corresponding inhibitory effects of R-flurbiprofen (RFP) are extremely weak $[14,15]$. The commercially available gel-type FP patch, which consists of a water-soluble polymer and water, has low percutaneous absorption and relative bioavailability of about $4 \%$ of that of the oral tablet [16]. The SFPP was developed in the form of a tape-type patch, consisting of a hydrophobic polymer without water, and SFP dissolved in minimal amount of solvent, to achieve highly improved percutaneous absorption and superior penetration into deep tissue. In animal studies, the SFPP produced high percutaneous absorption, penetration into deep inflammatory tissue, analgesic activity, and anti-inflammatory activity (submitted).

The present studies were aimed at elucidating the plasma pharmacokinetics and deep tissue penetration of the SFPP in humans. First, the pharmacokinetic profile of the SFPP after a single application to the lower back of healthy adult volunteers was examined (study 1). Next, concentrations of SFP in deep tissues (synovial tissue and synovial fluid) were examined in patients with knee OA scheduled for total knee arthroplasty and compared to those produced by a gel-type FP patch which contains the same amount of SFP and is commercially available in European companies, South Africa, and Japan for many years (study 2).

\section{Methods}

\section{Test patches}

SFPP tape-type patches containing 2, 5, 10, and $20 \mathrm{mg}$ of SFP, placebo patches containing no SFP, and FP gel-type patches $\left(\right.$ Stayban $^{\circledR}$ ) containing $40 \mathrm{mg}$ of FP were manufactured by Tokuhon Corporation (Tokyo, Japan). With the limitation of solubility of SFP, maximum SFP content was limited to $20 \mathrm{mg}$ per patch (size $7 \mathrm{~cm} \times 10 \mathrm{~cm}$ ).

\section{Study design}

\section{Study 1: pharmacokinetic study in healthy volunteers}

The study protocol was approved by the Institutional Review Board (IRB) of the Bio-Iatoric Center at Kitasato Institute (Tokyo, Japan) and conducted at the Bio-Iatoric Center at Kitasato Institute. The study was conducted according to the Declaration of Helsinki and Good Clinical Practice guidelines. Healthy adult male volunteers aged $20-35$ years were included in the study. Those who had skin wounds, acne, or other abnormalities at the site of application (lower back) and those who had used any other drug within the week prior to the application of the study drug were excluded from the study.

SFPP tape-type patches $(7 \mathrm{~cm} \times 10 \mathrm{~cm})$, containing 2,5 , 10 , or $20 \mathrm{mg}$ of SFP, were used in this study. To evaluate 6 dose regimens $(2,5,10,20,40$, and $60 \mathrm{mg})$, one sheet of 2-, $5-, 10-$, or 20-mg patches was applied for the $2-20 \mathrm{mg}$ dose regimens, whereas 2 and 3 sheets of $20-\mathrm{mg}$ patches were applied for the 40-mg and 60-mg dose regimens, respectively. A placebo patch containing no SFP was also used as the comparator for safety evaluation.

After written consent was obtained, 30 healthy male volunteers were enrolled in a randomized, single-blinded, placebo-controlled, dose-escalation phase 1 study. Each subject was applied two times at the interval of 2 weeks. The subjects were allocated to 3 groups of 10 persons each and were randomly given the SFPP $(n=7)$ or placebo $(n=3)$ at two steps (group $12 \mathrm{mg} / 5 \mathrm{mg}$; group $210 \mathrm{mg} / 20 \mathrm{mg}$; group $340 \mathrm{mg}$ / $60 \mathrm{mg}$ ) (Fig. 1).

The SFPP or placebo patch was applied to the lower back for $24 \mathrm{~h}$. Blood samples were collected $1 \mathrm{~h}$ before application and at 2, 4, 6, 8, 10, 12, 14, 24, 28, 32, 36, 47, and $71 \mathrm{~h}$ after application ( $5 \mathrm{~mL}$ on each occasion). The collected blood samples were centrifuged immediately. Plasma samples were stored at approximately $-20^{\circ} \mathrm{C}$ until SFP concentrations were measured. The applied patches were collected to calculate the percutaneous absorption ratio.

\section{Study 2: tissue concentration study for knee $O A$}

The study protocol was approved by the IRB of Eniwa Hospital (Hokkaido, Japan), and the study was conducted at Eniwa Hospital. The study was conducted according to the Declaration of Helsinki and Good Clinical Practice guidelines.

The study included patients with knee OA scheduled for unilateral total knee arthroplasty. Patients who had a history of surgery (excluding arthroscopic-assisted surgery) of the target knee and those who had received FP or undergone arthroscopic examination, centesis, or drainage of the target knee within 7 days prior to the application of the study drug were excluded.

SFPPs $(10 \mathrm{~cm} \times 14 \mathrm{~cm})$, containing $20 \mathrm{mg}$ of SFP, were used in the study. The comparator FP patch was the Stayban ${ }^{\text {B }}$ pap $(10 \mathrm{~cm} \times 14 \mathrm{~cm})$ gel-type patch containing $40 \mathrm{mg}$ of FP. The SFP content was identical $(20 \mathrm{mg})$ in the tested patches.

Twenty patients who gave written consent were included in this randomized open-label, parallel group comparative study. SFPPs and FP patches were cut in half $(7 \mathrm{~cm} \times 10 \mathrm{~cm})$ and applied to the target knee at a site about $2 \mathrm{~cm}$ distant from the intended incision line on the right and left sides. SFPPs and FP patches were applied to 10 patients each, after which the SFP concentration in deep tissue of the knee and safety were evaluated.

The patches were applied for $12 \mathrm{~h}$, which approximated $t_{\max }$ on the basis of the pharmacokinetic parameters of the FP patch [17] and the pharmacokinetic parameters of the SFPP determined in a single application study (study 1). Each patch was removed just before surgery. Synovial tissue, 
Group 1

Step 1-1

$2 \mathrm{mg}: n=7$

Placebo: $n=3$

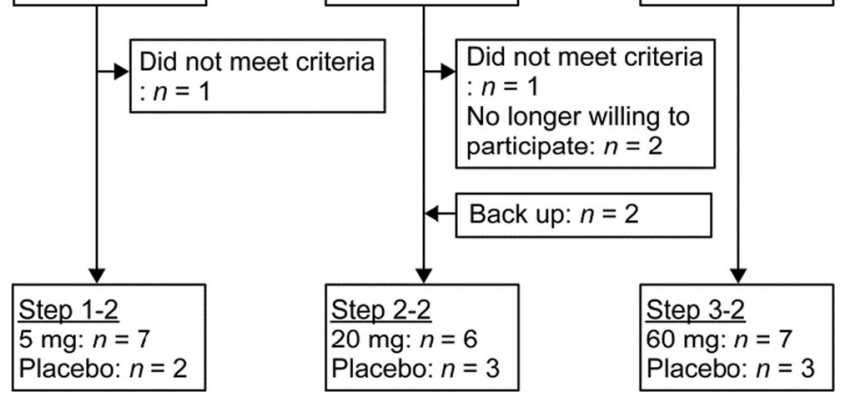

Fig. 1 Flow chart of study 1

synovial fluid, and plasma were collected at the time of surgery and stored at approximately $-20^{\circ} \mathrm{C}$ until SFP concentrations were measured. The applied patches were collected to calculate the percutaneous absorption ratio.

\section{Analytical methods}

\section{Study 1}

The SFP concentrations in the plasma and patches were determined by high-performance liquid chromatography (HPLC) at Sumika Chemical Analysis Service, Ltd. (Osaka, Japan). The validated SFP plasma concentration range was $2-$ $800 \mathrm{ng} / \mathrm{mL}$, intra-run precision was $\leq 4.8 \%$, and intra-run accuracy was -6.2 to $10.0 \%$. The validated SFP concentration range in a sheet of the patch was $0.2-25 \mathrm{mg}$, with intrarun precision of $\leq 2.4 \%$ and intra-run accuracy of -9.5 to $5.0 \%$ (further details are provided in supplementary documents).

\section{Study 2}

The SFP concentrations in tissue and plasma were determined by liquid chromatography and mass spectrometry (LC-MS/ MS) and the SFP and FP concentrations in the patches were determined by HPLC at Taisho Pharmaceutical Co., Ltd. (Tokyo, Japan). The validated SFP concentration range was 5-10, $000 \mathrm{ng} / \mathrm{g}$ for synovial tissue and $0.5-1000 \mathrm{ng} / \mathrm{mL}$ for synovial fluid and plasma. Intra-run precision and intra-run accuracy were $\leq 3.3 \%$ and -2.5 to $6.1 \%$ for synovial tissue, $\leq 4.4 \%$ and -4.6 to $1.7 \%$ for synovial fluid, and $\leq 4.7 \%$ and 1.2 to $11.6 \%$ for plasma. The range of validated drug concentrations in a patch sheet was 8-48 mg of SFP for the SFPP and 22.4$40 \mathrm{mg}$ of FP for the FP patch. Intra-run precision and intra-run accuracy were $\leq 0.6 \%$ and -0.4 to $1.6 \%$ for the SFPP and $\leq 0.3 \%$ and 0.9 to $1.9 \%$ for the FP patch (further details are provided in supplementary documents).

\section{Pharmacokinetic analysis}

Pharmacokinetic parameters were calculated as follows. $\mathrm{C}_{\max }$ and $\mathrm{t}_{\max }$ were obtained directly from the plasma concentration. The elimination rate constant $(\lambda z)$ was obtained by loglinear regression of the terminal phase of the plasma concentration-time curve. The $t_{1 / 2}$ was calculated as $\ln 2 / \lambda z$. $\mathrm{AUC}_{0-\infty}$ was calculated as the sum of the area from time zero to the last quantifiable time point $t$ obtained by the trapezoidal method, and the area from $t$ to infinite time calculated from $\mathrm{Ct} /$ $\lambda z ; \mathrm{Ct}$ is the last observed quantifiable concentration.

The percutaneous absorption ratio was calculated from the SFP amount in the patch (A) and the residual amount in the used patch (B) according to the following equation:

Absorption ratio $(\%)=\frac{(\mathrm{A}-\mathrm{B})}{\mathrm{A}} \times 100$

\section{Statistical analysis}

\section{Study 1}

Descriptive statistics for plasma concentrations, pharmacokinetic parameters, and absorption were calculated by dose group. Dose proportionality for $\mathrm{C}_{\max }$ and $\mathrm{AUC}_{0-\infty}$ was evaluated by determining whether the two-sided $95 \%$ confidence

Table 1 Subject demographics (study 1)

\begin{tabular}{|c|c|c|c|c|c|c|}
\hline & \multicolumn{2}{|l|}{ Group 1} & \multicolumn{2}{|l|}{ Group 2} & \multicolumn{2}{|l|}{ Group 3} \\
\hline & $2 \mathrm{mg}(n=7)$ & $5 \mathrm{mg}(n=7)$ & $10 \mathrm{mg}(n=7)$ & $20 \mathrm{mg}(n=6)$ & $40 \mathrm{mg}(n=7)$ & $60 \mathrm{mg}(n=7)$ \\
\hline Age (years) & $\begin{array}{l}23.0 \pm 3.7 \\
(20-30)\end{array}$ & $\begin{array}{l}22.9 \pm 2.5 \\
(20-26)\end{array}$ & $\begin{array}{l}22.3 \pm 2.1 \\
(20-26)\end{array}$ & $\begin{array}{l}22.5 \pm 1.9 \\
(21-26)\end{array}$ & $\begin{array}{l}24.1 \pm 3.3 \\
(21-30)\end{array}$ & $\begin{array}{l}23.3 \pm 2.3 \\
(21-26)\end{array}$ \\
\hline Weight (kg) & $\begin{array}{l}61.01 \pm 8.07 \\
(53.0-74.7)\end{array}$ & $\begin{array}{l}61.93 \pm 8.36 \\
(51.4-74.7)\end{array}$ & $\begin{array}{l}63.89 \pm 6.70 \\
(54.8-72.9)\end{array}$ & $\begin{array}{l}61.48 \pm 7.55 \\
(54.4-72.9)\end{array}$ & $\begin{array}{l}58.54 \pm 4.37 \\
(53.1-66.6)\end{array}$ & $\begin{array}{l}60.39 \pm 6.73 \\
(50.4-70.7)\end{array}$ \\
\hline $\mathrm{BMI}\left(\mathrm{kg} \mathrm{m}^{-2}\right)$ & $\begin{array}{l}21.19 \pm 2.07 \\
(18.9-24.9)\end{array}$ & $\begin{array}{l}21.06 \pm 2.48 \\
(17.7-24.9)\end{array}$ & $\begin{array}{l}21.45 \pm 1.95 \\
(19.1-24.4)\end{array}$ & $\begin{array}{l}20.97 \pm 2.27 \\
(18.6-24.4)\end{array}$ & $\begin{array}{l}20.06 \pm 0.82 \\
(19.2-21.7)\end{array}$ & $\begin{array}{l}20.25 \pm 1.15 \\
(18.7-21.7)\end{array}$ \\
\hline
\end{tabular}

Mean \pm SD (range) 


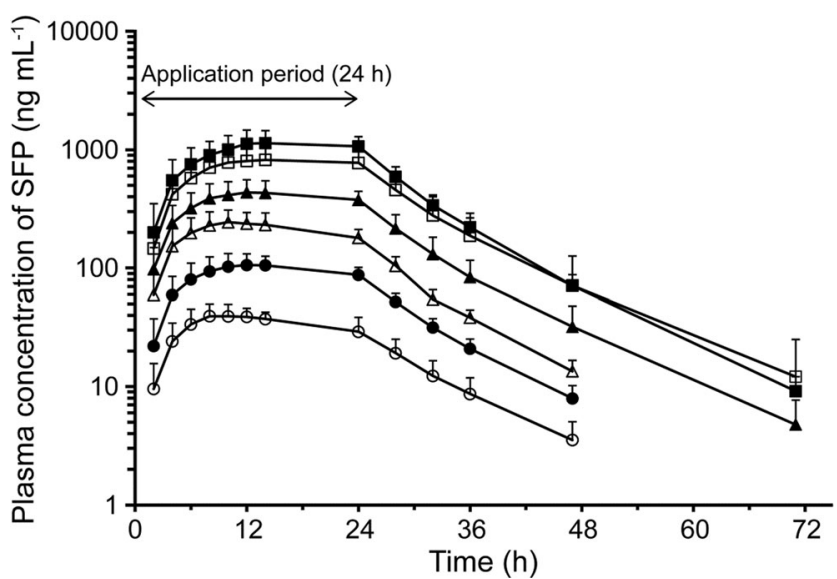

Fig. 2 Plasma concentrations of SFP (mean + SD, log scale) vs. time profiles $24 \mathrm{~h}$ after topical application of the SFPP (2 $\mathrm{mg}$ (white circle), $5 \mathrm{mg}$ (filled circle), $10 \mathrm{mg}$ (white triangle), $20 \mathrm{mg}$ (filled triangle), $40 \mathrm{mg}$ (white square), and $60 \mathrm{mg}$ (filled square))

intervals (CI) of regression coefficient estimates for these parameters did or did not include 1 using the power model.

\section{Study 2}

All analyses were carried out using $\mathrm{SAS}^{\circledR}$ 9.1.3. Statistical comparisons between groups were made using Welch's $t$ test because it could be assumed that the absorption ratios achieved by the SFPP and FP patches were quite different. Therefore, below-the-limit-of-quantification (BLQ) data was imputed using the lower limit of quantification (LLOQ; $5.0 \mathrm{ng} \mathrm{g}^{-1}$ for synovial tissue and $0.500 \mathrm{ng} \mathrm{mL}^{-1}$ for synovial fluid and plasma) when the concentration was BLQ, to avoid skewing the results for the FP patch. The significance level was set at $5 \%$ (two-sided).

\section{Results}

\section{Study 1}

In this study, 32 healthy adult volunteers (a cumulative total of 58 subjects at all steps in group 1, group 2, and group 3) were examined (Fig. 1). Table 1 shows the demographics of the
Table 3 Regression coefficients $(95 \% \mathrm{CI})$ of $\mathrm{C}_{\max }$ and $\mathrm{AUC}_{0-\infty}$

\begin{tabular}{cll}
\hline Dose range $(\mathrm{mg})$ & \multicolumn{2}{l}{ Regression coefficients $(95 \% \mathrm{CI})$} \\
\cline { 2 - 3 } & $\mathrm{C}_{\max }$ & $\mathrm{AUC}_{0-\infty}$ \\
\hline $2-20^{1}$ & $1.0175(0.9154-1.1197)$ & $1.0483(0.9564-1.1402)$ \\
$20-60^{2}$ & $0.9042(0.6437-1.1647)$ & $0.8719(0.5926-1.1513)$ \\
$2-60$ & $0.9679(0.9076-1.0282)$ & $0.9910(0.9303-1.0517)$ \\
\hline
\end{tabular}

${ }^{1}$ One sheet of 2-, 5-, 10-, or 20-mg patches

21,2 , and 3 sheets of $20-\mathrm{mg}$ patches

subjects (cumulative total, 41) in whom the plasma SFP concentration was determined after application of the SFPP.

The mean plasma concentrations vs. time profiles and pharmacokinetic parameters of SFP are shown in Fig. 2 and Table 2 , respectively. The $t_{\max }$ and $t_{1 / 2}$ values for the plasma SFP concentration were $10.3-17.7 \mathrm{~h}$ and $7.6-8.4 \mathrm{~h}$, respectively. The percutaneous absorption ratio, determined based on the residual amount of SFP in the patch, was $51.4-72.2 \%$.

The dose proportionality of $\mathrm{C}_{\max }$ and $\mathrm{AUC}_{0-\infty}$ was examined using a power model. Table 3 shows the regression coefficients $(95 \% \mathrm{CI})$ of $\mathrm{C}_{\max }$ and $\mathrm{AUC}_{0-\infty}$ at the dose range 2 $20 \mathrm{mg}, 20-60 \mathrm{mg}$, and 2-60 mg. For 2-20 mg, only the SFP content in the patches were different. For 20-60 mg, only the number of patch was different which means the application area was enlarged to increase the dose. The $95 \% \mathrm{CI}$ in each range includes 1 , showing dose proportionality, respectively. In addition, although the application area and the SFP content of the patches were different, dose proportionality was confirmed at the dose range of 2-60 mg.

With regard to safety, cutaneous symptoms were the major adverse reactions found at the site of topical application in the SFPP (36.6 \%, 15/41 subjects) and placebo groups (41.2 \%, $7 / 17$ subjects). Mild erythema was the most common cutaneous symptom ( $72.7 \%, 16 / 22$ subjects) and recovered promptly without any treatment.

\section{Study 2}

This study included 20 patients with knee OA scheduled for total knee arthroplasty. One patient was excluded from pharmacokinetic analysis due to the prior use of the patch

Table 2 Pharmacokinetic parameters and absorption ratios of SFP after topical application of the SFPP (24 h)

\begin{tabular}{lcccccc}
\hline & $2 \mathrm{mg}(n=7)$ & $5 \mathrm{mg}(n=7)$ & $10 \mathrm{mg}(n=7)$ & $20 \mathrm{mg}(n=6)$ & $40 \mathrm{mg}(n=7)$ & $60 \mathrm{mg}(n=7)$ \\
\hline $\left.\mathrm{C}_{\max }(\mathrm{ng} \mathrm{mL})^{-1}\right)$ & $43.3 \pm 7.1$ & $114.5 \pm 20.3$ & $248.0 \pm 63.5$ & $444.1 \pm 120.3$ & $858.2 \pm 235.8$ & $1187.7 \pm 294.6$ \\
$\mathrm{t}_{\max }(\mathrm{h})$ & $13.7 \pm 7.2$ & $15.1 \pm 6.2$ & $10.3 \pm 1.4$ & $14.7 \pm 4.7$ & $17.7 \pm 6.0$ & $16.3 \pm 5.3$ \\
$\mathrm{t}_{1 / 2}(\mathrm{~h})$ & $8.3 \pm 0.9$ & $7.8 \pm 1.2$ & $7.8 \pm 1.1$ & $8.4 \pm 0.5$ & $8.4 \pm 1.1$ & $7.6 \pm 0.4$ \\
$\mathrm{AUC}_{0-\infty}\left(\mathrm{ng} \mathrm{mL}^{-1} \mathrm{~h}\right)$ & $1051.0 \pm 156.7$ & $2801.4 \pm 414.2$ & $6055.8 \pm 1422.8$ & $11,705.3 \pm 3054.3$ & $23,129.8 \pm 7854.7$ & $30,236.9 \pm 7429.7$ \\
Absorption ratio (\%) & $61.2 \pm 10.7$ & $68.0 \pm 12.4$ & $72.2 \pm 10.5$ & $64.1 \pm 10.5$ & $57.5 \pm 9.3$ & $51.4 \pm 7.9$ \\
\hline
\end{tabular}

Mean \pm SD 
Table 4 Subject demographics (study 2)

\begin{tabular}{lll}
\hline & SFPP $(n=10)$ & FP $(n=9)$ \\
\hline Male/female & $1 / 9$ & $0 / 9$ \\
Age (years) & $72.2 \pm 6.4$ & $72.0 \pm 6.8$ \\
& $(60-80)$ & $(59-78)$ \\
Weight $(\mathrm{kg})$ & $69.23 \pm 15.77$ & $62.53 \pm 3.66$ \\
& $(42.7-102.8)$ & $(57.1-69.3)$ \\
BMI $\left(\mathrm{kg} \mathrm{m}^{-2}\right)$ & $29.74 \pm 5.38$ & $28.51 \pm 1.67$ \\
& $(23.0-41.2)$ & $(26.1-31.0)$ \\
\hline
\end{tabular}

Mean \pm SD (range)

containing FP, which was prohibited. The subject demographics of each group are shown in Table 4.

Table 5 shows the SFP concentrations in each tissue and absorption ratios after topical application. Because the synovial fluid could not be collected in one of the subjects in the SFPP group, the calculation included 9 subjects. The SFP concentration in synovial tissue after application of the FP patch was BLQ in 8 of 9 subjects. Therefore, the LLOQ $\left(5 \mathrm{ng} \mathrm{g}^{-1}\right)$ was used in the calculation according to the statistical analysis plan.

The SFP concentrations in synovial tissue, synovial fluid, and plasma after topical application of the SFPP were significantly higher $(p<0.05)$ than those achieved by the FP patch, with mean values 14.8-, 32.7-, and 34.5-fold higher, respectively. The percutaneous absorption ratio of the SFPP was also significantly higher $(p<0.05)$ than that of the FP patch, with a mean value 7.6 -fold higher.

With regard to safety, there were no adverse reactions in either group.

\section{Discussion}

Plasma SFP concentrations in healthy adult volunteers after a single topical application of the SFPP for $24 \mathrm{~h}$ were dose proportional and sustained throughout the topical application period. The results showed that the SFPP has a favorable pharmacokinetic profile allowing once-daily application.

The formulation of topical NSAIDs is known to greatly affect their percutaneous absorption [18]. The SFPP and FP patch showed marked differences in percutaneous absorption and tissue penetration, which were likely primarily due to differences in the patch formulations. The SFPP is a tapetype patch, whereas the FP patch is a gel-type patch. It is presumed that high concentrations of lipophilic SFP dissolved in the patch (consisting of a hydrophobic polymer) contributed to the high percutaneous absorption and tissue penetration achieved by the SFPP. In addition, medium-chain fatty acid ester, a penetration enhancer [19], was used as an additive in the SFPP and may have contributed to the observed improvement in percutaneous absorption.

Bolten reported the FP concentrations in synovial fluid and serum after topical application of a gel-type FP patch in patients who required surgery for knee OA and orthopedic disease [10]. The reported data are tissue concentrations of FP; the ratio of SFP concentration to RFP concentration is unclear. However, considering that the ratio of SFP $C_{\max }$ to RFP $\mathrm{C}_{\max }$ after oral administration of FP was 1.05 [20], and there was no chiral inversion of enantiomers [21], the SFP concentration was estimated as half of the FP concentration. According to this estimation, the SFP concentrations in synovial fluid and plasma $12 \mathrm{~h}$ after topical application of the FP patch in our study were similar to those reported by Bolten.

$\mathrm{C}_{\max }$ and $\mathrm{AUC}_{0-\infty}$ after oral administration of SFP $50 \mathrm{mg}$ in gelatin capsule were reported as $9.3 \mu \mathrm{g} \mathrm{mL}{ }^{-1}$ and $55.2 \mu \mathrm{g} \mathrm{h} \mathrm{mL}^{-1}$, respectively [21]. As dose proportionality was observed in the SFPP, $\mathrm{C}_{\max }$ and $\mathrm{AUC}_{0-\infty}$ after application of the SFPP $50 \mathrm{mg}$ could be proportionally calculated from those of the SFPP $40 \mathrm{mg}$ and $60 \mathrm{mg}$ as $1.0 \mu \mathrm{g} \mathrm{mL}^{-1}$ and $26.7 \mu \mathrm{g} \mathrm{h} \mathrm{mL}{ }^{-1}$. The pharmacokinetic parameters ratios (SFP oral administration/SFPP) are approximately 9 for $\mathrm{C}_{\max }$ and 2 for $\mathrm{AUC}_{0-\infty}$, which mean smaller values are observed in the SFPP. It was reported that the plasma concentration after repeated application of FP patch was 2.5 times higher than that after single application [16]. So it must be important to study the pharmacokinetics after repeated application of SFPP.
Table 5 SFP concentrations in each tissue type and absorption ratios after topical application of the SFPP or FP patch $(12 \mathrm{~h})$

\begin{tabular}{lcllll}
\hline & SFFP $(n=10)$ & & FP $(n=9)$ & & $P$ value \\
\hline Synovial tissue $\left(\mathrm{ng} \mathrm{g}^{-1}\right)$ & $84.5 \pm 56.0$ & $(44.5,125)$ & $5.70 \pm 2.10^{\mathrm{a}}$ & $(-)^{\mathrm{a}}$ & 0.002 \\
Synovial fluid $\left(\mathrm{ng} \mathrm{mL}^{-1}\right)$ & $149 \pm 44.9^{\mathrm{b}}$ & $(114,183)$ & $4.55 \pm 3.66$ & $(1.74,7.37)$ & $<0.001$ \\
Plasma (ng mL $\left.\mathrm{mL}^{-1}\right)$ & $362 \pm 84.8$ & $(302,423)$ & $10.5 \pm 10.1$ & $(2.74,18.3)$ & $<0.001$ \\
Absorption ratio (\%) & $44.46 \pm 10.63$ & $(36.85,52.07)$ & $5.82 \pm 1.64$ & $(4.56,7.08)$ & $<0.001$ \\
\hline
\end{tabular}

Mean \pm SD $(95 \% \mathrm{CI})$

LLOQ, $5.0 \mathrm{ng} \mathrm{g}^{-1}$ for synovial tissue and $0.500 \mathrm{ng} \mathrm{mL}^{-1}$ for synovial fluid and plasma

${ }^{a}$ Eight samples of synovial tissue (FP) contained SFP below the limit of quantitation, so $5.0 \mathrm{ng} \mathrm{g}^{-1}$ (LLOQ) was used to calculate the mean and SD (95\% CI was not calculated)

${ }^{\mathrm{b}} n=9$ (one subject's synovial fluid could not be collected) 
In this study, we measured SFP concentrations in synovial tissue and synovial fluid at a single time point around $t_{\max }$ (12 h after topical application), without conducting measurements at other time points. Because plasma SFP concentrations were similar 12 and $24 \mathrm{~h}$ after topical application of the SFPP for $24 \mathrm{~h}$, it is speculated that the SFP concentrations in synovial tissue and synovial fluid persist in the same manner as the plasma SFP concentration.

In conclusion, topical application of the SFPP for $24 \mathrm{~h}$ provided a persistent high plasma concentration of SFP in a dose-proportional manner. In addition, the SFP concentrations in synovial tissue and synovial fluid after application of the SFPP, as well as the percutaneous absorption ratio of SFP, were significantly higher than those after application of the FP patch. It is expected that the SFPP may exert a potent anti-inflammatory and analgesic effect by achieving penetration of a high concentration of SFP into deep synovial tissue, the site of inflammation in patients with knee OA.

Acknowledgments The authors would like to thank Takuya Hirose and Kenji Tomatsu of Taisho Pharmaceutical Co., Ltd. for their assistance with drafting and revising this manuscript.

\section{Compliance with ethical standards}

Funding Study 1 was funded by Mitsubishi Tanabe Pharma Corporation (MTPC) and study 2 was funded by Taisho Pharmaceutical Co., Ltd. (TP).

Conflict of interest IY, NO, and IM are employees of TP. MK and IY are employees of MTPC. SS and KU have no competing interests. HM has received consultancy fees from TP and YH received consultancy fees from TP while at the author's previous affiliation. There are no other relationships or activities that could appear to have influenced the submitted work.

Ethical approval The study 1 protocol was approved by the Institutional Review Board (IRB) of the Bio-Iatoric Center at Kitasato Institute (Tokyo, Japan) and conducted at the Bio-Iatoric Center at Kitasato Institute. The study 2 protocol was approved by the IRB of Eniwa Hospital and conducted at Eniwa Hospital. Both studies were conducted according to the Declaration of Helsinki and Good Clinical Practice guidelines.

Open Access This article is distributed under the terms of the Creative Commons Attribution 4.0 International License (http:// creativecommons.org/licenses/by/4.0/), which permits unrestricted use, distribution, and reproduction in any medium, provided you give appropriate credit to the original author(s) and the source, provide a link to the Creative Commons license, and indicate if changes were made.

\section{References}

1. Peat G, McCarney R, Croft P (2001) Knee pain and osteoarthritis in older adults: a review of community burden and current use of primary health care. Ann Rheum Dis 60:91-97
2. Muraki S, Akune T, Oka H, En-yo Y, Yoshida M, Saika A, Suzuki T, Yoshida H, Ishibashi H, Tokimura F, Yamamoto S, Nakamura K, Kawaguchi H, Yoshimura N (2010) Association of radiographic and symptomatic knee osteoarthritis with health-related quality of life in a population-based cohort study in Japan: the ROAD study. Osteoarthr Cartil 18:1227-1234

3. American Academy of Orthopaedic Surgeons. Treatment of osteoarthritis of the knee, evidence-based guideline 2nd edition (issue date 18 May 2013). Available at http://www.aaos. org/research/guidelines/GuidelineOAKnee.asp. Accessed 9 August 2015

4. National Institute for Health and Clinical Excellence (NICE). Osteoarthritis: care and management in adults. NICE clinical guideline 177 (issue date February 2014). Available at http://www.nice. org.uk/guidance/CG177 Accessed 9 August 2015

5. McAlindon TE, Bannuru RR, Sullivan MC, Arden NK, Berenbaum F, Bierma-Zeinstra SM, Hawker GA, Henrotin Y, Hunter DJ, Kawaguchi H, Kwoh K, Lohmander S, Rannou F, Roos EM, Underwood M (2014) OARSI guidelines for the non-surgical management of knee osteoarthritis. Osteoarthr Cartil 22:363-388

6. Torres L, Dunlop DD, Peterfy C, Guermazi A, Prasad P, Hayes KW, Song J, Cahue S, Chang A, Marshall M, Sharma L (2006) The relationship between specific tissue lesions and pain severity in persons with knee osteoarthritis. Osteoarthr Cartil 14:1033-1040

7. de Lange-Brokaar BJ, Ioan-Facsinay A, van Osch GJ, Zuurmond AM, Schoones J, Toes RE, Huizinga TW, Kloppenburg M (2012) Synovial inflammation, immune cells and their cytokines in osteoarthritis: a review. Osteoarthr Cartil 20:1484-1499

8. Kai S, Kondo E, Kawaguchi Y, Kitamura N, Yasuda K (2013) Flurbiprofen concentration in soft tissues is higher after topical application than after oral administration. Br J Clin Pharmacol 75: 799-804

9. Efe T, Sagnak E, Roessler PP, Getgood A, Patzer T, FuchsWinkelmann S, Peterlein CD, Schofer MD (2014) Penetration of topical diclofenac sodium $4 \%$ spray gel into the synovial tissue and synovial fluid of the knee: a randomised clinical trial. Knee Surg Sports Traumatol Arthrosc 22:345-350

10. Bolten W (1994) The pharmacokinetics, pharmacodynamics and comparative efficacy of flurbiprofen LAT. Br J Clin Pract 48:190 195

11. Miyatake S, Ichiyama H, Kondo E, Yasuda K (2009) Randomized clinical comparisons of diclofenac concentration in the soft tissues and blood plasma between topical and oral applications. Br J Clin Pharmacol 67:125-129

12. Sekiya I, Morito T, Hara K, Yamazaki J, Ju YJ, Yagishita K, Mochizuki T, Tsuji K, Muneta T (2010) Ketoprofen absorption by muscle and tendon after topical or oral administration in patients undergoing anterior cruciate ligament reconstruction. AAPS PharmSciTech 11:154-158

13. Rolf C, Engström B, Beauchard C, Jacobs LD, Le Liboux A (1999) Intra-articular absorption and distribution of ketoprofen after topical plaster application and oral intake in 100 patients undergoing knee arthroscopy. Rheumatology 38:564-567

14. Peskar BM, Kluge S, Peskar BA, Soglowek SM, Brune K (1991) Effects of pure enantiomers of flurbiprofen in comparison to racemic flurbiprofen on eicosanoid release from various rat organs ex vivo. Prostaglandins 42:515-531

15. Carabaza A, Cabré F, Rotllan E, Gómez M, Gutiérrez M, García ML, Mauleón D (1996) Stereoselective inhibition of inducible cyclooxygenase by chiral nonsteroidal antiinflammatory drugs. J Clin Pharmacol 36:505-512

16. Taburet AM, Singlas E, Glass RC, Thomas F, Leutenegger E (1995) Pharmacokinetic comparison of oral and local action transcutaneous flurbiprofen in healthy volunteers. J Clin Pharm Ther 20:101-107 
17. Medicine Interview Form of Stayban ${ }^{\circledR}$ Pap $40 \mathrm{mg}$. Revised by Taisho Toyama Pharmaceutical Co., Ltd. in March 2014 (Version 3). Opened in the Website of Pharmaceuticals and Medical Devices Agency, Japan. Available at http://www. pmda.go.jp/Accessed 9 August 2015

18. Haroutiunian S, Drennan DA, Lipman AG (2010) Topical NSAID therapy for musculoskeletal pain. Pain Med 11:535-549

19. Lane ME (2013) Skin penetration enhancers. Int J Pharm 447:12-21
20. Knadler MP, Brater DC, Hall SD (1992) Stereoselective disposition of flurbiprofen in normal volunteers. Br J Clin Pharmacol 33:369-375

21. Geisslinger G, Lötsch J, Menzel S, Kobal G, Brune K (1994) Stereoselective disposition of flurbiprofen in healthy subjects following administration of the single enantiomers. Br J Clin Pharmacol 37:392-394 